\title{
(6) OPEN ACCESS \\ Transition from childhood to adulthood in coeliac disease: the Prague consensus report
}

\author{
Jonas F Ludvigsson, ${ }^{1,2,3}$ Lars Agreus, ${ }^{4}$ Carolina Ciacci, ${ }^{5}$ Sheila E Crowe, ${ }^{6}$ \\ Marilyn G Geller, ${ }^{7}$ Peter H R Green, ${ }^{8}$ Ivor Hill, ${ }^{9}$ A Pali Hungin, ${ }^{10}$ Sibylle Koletzko, ${ }^{11}$ \\ Tunde Koltai, ${ }^{12}$ Knut E A Lundin, ${ }^{13}$ M Luisa Mearin, ${ }^{14}$ Joseph A Murray, ${ }^{15}$ \\ Norelle Reilly, ${ }^{16}$ Marjorie M Walker, ${ }^{17}$ David S Sanders, ${ }^{18}$ Raanan Shamir, ${ }^{19}$ \\ Riccardo Troncone, ${ }^{20}$ Steffen Husby ${ }^{21}$
}

- Additional material is published online only. To view please visit the journal online (http://dx.doi.org/10.1136/ gutjnl-2016-311574).

For numbered affiliations see end of article.

\section{Correspondence to} Dr Jonas F Ludvigsson, Department of Medical Epidemiology and Biostatistics, Karolinska Institutet, Stockholm 17177, Sweden; jonasludvigsson@yahoo.com Dr Steffen Husby, Hans Christian Andersen Children's Hospital, Odense University Hospital, DK-5000 Odense, Denmark;

Steffen.Husby@rsyd.dk

Received 1 February 2016 Revised 23 March 2016 Accepted 27 March 2016 Published Online First 18 April 2016
CrossMark

\footnotetext{
To cite: Ludvigsson JF, Agreus L, Ciacci C, et al. Gut 2016:65:1242-1251.
}

\section{ABSTRACT}

The process of transition from childhood to adulthood is characterised by physical, mental and psychosocial development. Data on the transition and transfer of care in adolescents/young adults with coeliac disease (CD) are scarce. In this paper, 17 physicians from 10 countries (Sweden, Italy, the USA, Germany, Norway, the Netherlands, Australia, Britain, Israel and Denmark) and two representatives from patient organisations (Association of European Coeliac Societies and the US Celiac Disease Foundation) examined the literature on transition from childhood to adulthood in CD. Medline (Ovid) and EMBASE were searched between 1900 and September 2015. Evidence in retrieved reports was evaluated using the Grading of Recommendation Assessment, Development and Evaluation method. The current consensus report aims to help healthcare personnel manage CD in the adolescent and young adult and provide optimal care and transition into adult healthcare for patients with this disease. In adolescence, patients with CD should gradually assume exclusive responsibility for their care, although parental support is still important. Dietary adherence and consequences of non-adherence should be discussed during transition. In most adolescents and young adults, routine small intestinal biopsy is not needed to reconfirm a childhood diagnosis of CD based on European Society for Pediatric Gastroenterology, Hepatology and Nutrition (ESPGHAN) or North American Society for Pediatric Gastroenterology, Hepatology and Nutrition (NASPGHAN) criteria, but a biopsy may be considered where paediatric diagnostic criteria have not been fulfilled, such as, in a patient without biopsy at diagnosis, additional serology (endomysium antibody) has not been performed to confirm 10-fold positivity of tissue transglutaminase antibodies or when a no biopsy strategy has been adopted in an asymptomatic child.

\section{INTRODUCTION}

The Child and Adolescent Health Measurement Initiative estimates that one million US children with special health needs make the transition to adult care every year. ${ }^{1}$ A large proportion of adolescents/young adults, however, have not been sufficiently prepared for the transfer to adult care. ${ }^{2} 3$

Coeliac disease $(\mathrm{CD})^{4}$ is one of the most common chronic disorders in childhood, and children with CD make up an important part of transition healthcare in the Western world. The overall prevalence of CD varies from $0.71 \%$ in the $\mathrm{USA}^{5}$ to as high as $2.9 \%$ in certain age groups in Sweden. ${ }^{6}$ Data also suggest that both diagnostic rates $^{7}$ and incidence of undiagnosed and diagnosed $\mathrm{CD}^{9} 10$ are increasing.

Generally, the transition from paediatric to adult care should be a collaborative process involving patients, their parents or caregivers, the physician and the dietician. ${ }^{11}$ This transition has also been made a top 10 priority by the American Academy of Pediatrics ${ }^{11}$ with dedicated programmes for patients and professionals (eg, the Bright Future Programme). There are several transition recommendations for chronic disease, ${ }^{12}{ }^{13}$ but very few for $\mathrm{CD},{ }^{14}$ and without comment on CD-specific aspects of different recommendations for diagnostics in childhood ${ }^{15}$ and adulthood. ${ }^{16} 17$

In this consensus report, we propose recommendations for the management of CD in adolescents and young adults, and how to facilitate the transition to adult healthcare for patients with CD.

\section{METHODS}

Seventeen physicians from 10 countries (Sweden, Israel, Italy, the USA, Germany, Norway, the Netherlands, Australia, Britain and Denmark) and 2 representatives from patient organisations (Association of European Coeliac Societies and the US Celiac Disease Foundation) examined the available literature on the transition from childhood to adulthood CD.

\section{Intent and levels of evidence}

We carefully weighed all aspects of the childhood to adulthood transition in relation to CD diagnosis and management. In conjunction with librarians at the Karolinska Institute, Sweden, we searched Medline (Ovid) and EMBASE between 1900 and September 2015 to identify the most relevant information for this review. The following search algorithm was used ("transition of care" or "transition of management" or "continuity of care") AND ("adolescence" or "pediatrics") AND ("celiac disease" or "coeliac disease") and identified 190 references. We also explored the literature on transitional issues in other paediatric fields and additional relevant literature. The working groups developed initial recommendations and rated the quality of evidence and strength according to the Grading of Recommendation Assessment, Development and Evaluation method. The quality 
of evidence for each statement was graded as high, moderate or low $(\mathrm{A}, \mathrm{B}, \mathrm{C}){ }^{18}$

Our consensus group consisted of paediatricians $(n=8$; JFL, IH, SK, MLM, NR, RS, RT, SH), adult gastroenterologists $(\mathrm{n}=6$; CC, SEC, PHRG, KEAL, JAM, DSS), two general practitioners (LA, APH), one histopathologist (MMW) and two representatives from a patient organisation (MGG, TK).

After an initial review of the literature, we formed working groups focusing on different topics (see online supplementary appendix). Each working group worked independently prior to a first draft created by JFL. All data and opinions were discussed among all coauthors to reach consensus. The content of this report was discussed through teleconferencing and at two gastroenterology meetings (Prague, June 2015; Barcelona, October 2015). All authors agreed on the conclusions of the report.

\section{RESULTS}

\section{Transfer of responsibility for self-care from the paediatric to the adolescent patient with CD}

Paediatric patients with $C D$ are usually seen by their general paediatrician and in a specialised centre by a team comprising a paediatric gastroenterologist, a specialised nurse, a dietician and, if needed, a social worker or psychologist. In children, the delivery of care is fundamentally family-centred, whereas in adulthood, responsibility becomes autonomous and dependent upon the needs of individuals. ${ }^{19}$

Adolescents typically start to seek independence as part of a structured family environment, but as adults they leave home, learn how to live with others and assume various responsibilities (eg, work and societal and financial commitments). ${ }^{20}$ The transition process should gradually parallel this evolution of becoming an adult and include an incremental increase in shifting knowledge and decisions to the adolescent patient with CD. ${ }^{19}$ The actual transfer may also be triggered by non-age-related factors, such as pregnancy, marriage, poor dietary adherence, substance abuse or dropping out from school. While none of these factors may signal maturity, they may draw the family's attention (and that of the family doctor) to the fact that the adolescent is entering adulthood. The physical, mental and psychosocial development when becoming an adolescent and ultimately an adult is central to transition. This development varies between individuals of the same age, and of note, children with a chronic disease may develop autonomy later than their peers. ${ }^{21}$

Both the family and the adolescent patient should be at the centre of transition, and the function of the clinician is to balance the parents' authority and the need for autonomy in the adolescent. Many adolescents/young adults have to work hard to overcome their reliance on their parents. To parents, this means stepping back and allowing their adolescent children to make independent decisions. Both overprotection and insufficient support of the child are undesirable.

In a joint statement, ${ }^{11}$ three physician organisations suggest that the physician starts a discussion about transition when the adolescent is $12-13$ years old, develop a transition plan when the child is 14-15, with the actual transfer taking place at $\geq 18$ years of age. We agree with this timeline, although cultural and social differences as well as individual patient preferences mean variations may occur. Transition is a complex process, and specific aims for transition in adolescents and young adults are listed in box 1.

Statement: The transition process should gradually parallel evolution of child to adult and include an incremental increase
Box 1 Specific aims for transition to adult care in

adolescents and young adults with coeliac disease

- Encourage maturation of communication and decision-making skills.

- Allow patients to take responsibility for medical self-management.

- Education and counselling of the adolescent/young adult to manage a gluten-free diet and consequences of non-adherence.

- Recognition and treatment of psychological problems: discouragement, feeling overwhelmed, anxiety about the future and complications such as depression and eating disorders.

- Show patients how to become familiar with the healthcare system, including environmental changes when they legally become an adult.

- Increase disease knowledge and its potential complications.

- Help the patient develop good health habits and self-care skills that encourage autonomy and establish good health habits.

- Address the family's anxieties or questions.

in transferring responsibility for self-care to the adolescent patient with $\mathrm{CD}$. (C)

Recommendation: We recommend to gradually transfer responsibility of medical care to the adolescent patient with CD.

\section{Growth and puberty}

Growth impairment is a known consequence of untreated or undertreated $\mathrm{CD}^{22} 23$ though many children with short stature diagnosed with CD in childhood demonstrate good catch-up growth. ${ }^{24}$ However, catch-up growth may occur more predictably for those with a delayed bone age at diagnosis and where growth velocity acceleration during the first year of treatment for CD is apparent. ${ }^{25}$ Untreated CD, or CD diagnosed after attainment of adult height, results in shorter adult height than seen in healthy controls, particularly among men. ${ }^{26}{ }^{27}$ While the precise pathophysiology may currently be poorly understood, some adolescents and young adults with CD will experience a delay in pubertal development ${ }^{28}$ and may continue to grow and sexually mature beyond the expected age of pubertal completion. ${ }^{29}$ This may have implications for emotional maturity, sexual health and menstrual regularity. At the time when transition is anticipated, the paediatric provider should provide data regarding the patient's history of physical development and should note to the adult provider whether the patient has achieved his or her final adult height. For those patients who have experienced significant pubertal delay where the paediatric provider may be better suited to provide guidance, it may be advisable to coordinate transition to an adult provider at the completion of puberty, particularly where other paediatric specialists such as endocrinologists continue to care for the patient to manage growth failure. A bone age X-ray may be done for cases of observed pubertal delay to inform growth expectations and timing of transition.

\section{Barriers to a successful transition in CD}

Several factors inhibit a successful transition; among them is having an adult healthcare provider without experience of the 
relevant disease. The paediatric healthcare provider should therefore help the adolescent identify a concerned and capable caregiver for adults. ${ }^{30} \mathrm{~A}$ transition programme can only be successful if organised with the active participation and interest of the adult healthcarers, ${ }^{20}$ who may be a gastroenterologist or a general practitioner.

One inherent barrier impeding an adolescent's communication with a health provider is the fear of being judged. Out of the fear of being judged by the adult physician, adolescents may be less likely to ask questions that could reveal a history of nonadherence with medical recommendations. ${ }^{31}$ The key here is to establish a regular communication channel between the adolescent/young adult and the adult physician.

The patients' impression of their provider influences the likelihood of effective communication of health information and patient concerns. Unsurprisingly, conflict with the healthcare provider has a negative impact on adherence to therapeutic regimens. 3233

Cultural distinctions between paediatric and adult providers have been noted, ${ }^{19}{ }^{30}$ where departure from a child to an adult environment with a greater expectation of patient independence may deter some families. Families of young adults with a variety of chronic conditions report relative decrease in support and availability for advice from their new adult provider. ${ }^{30}$ Some patients and parents, therefore, prefer to remain with their paediatrician. Ensuring that no adolescent drops out at transfer of care is crucial. ${ }^{11} 34$

Statement: The patients' impression of their provider influences the adherence and communication of health information and patient concerns. (C)

Recommendation: Healthcare providers are advised to consider that their demeanour is likely to influence patient concerns as well as the effectiveness of health information.

\section{The actual transfer of care}

There are differences between $\mathrm{CD}$ and other chronic diseases. For example, patients do not depend on particular medications with prescriptions and thus visits to a physician are not obligatory. In fact, many patients believe they have mastered the gluten-free diet (GFD) and have minimal contact with healthcare. In addition, non-adherence to diet may not cause symptoms for years, giving a false sense of security. Therefore, adolescents/young adults with $\mathrm{CD}$ are at risk of 'medical' dropout prior to and during transfer. ${ }^{11} 3435$ Meanwhile, adult services expect that their adult patients will be able to care for themselves and be capable of negotiating the hospital clinical system. So, clearly there is a need to bridge the gap between the paediatric and adult services. ${ }^{36}$ For adult gastroenterologists, $\mathrm{CD}$ is also often perceived as a less serious disease compared with GI cancer or IBD and knowledge may be limited with respect to complications, diet, inheritance, extraintestinal manifestations and how to monitor patients.

The actual transfer can take many forms. In some settings, the paediatric and adult gastroenterologists see the patient at the same visit; in others, paediatric and adult gastroenterologists meet annually to discuss patients in transition. Optimally, joint transition clinics with paediatric and adult service clinicians can be established for information delivery and generating trust in the new physician. ${ }^{37}$ Structured transitional models and targeted education are important and in other chronic diseases ${ }^{38-42}$ have been linked to improved care, better health outcome and improved health-related quality of life (QoL). One path to facilitate transition and transfer of care is to create a 'transition document', which would allow a smooth transfer of individual medical care data ${ }^{36}$ (see online supplementary appendix). Such a transition document should be created by the paediatrician prior to transfer, and at the minimum, contain details of the basis for the coeliac diagnosis and information during follow-up such as serology, anthropometric data, comorbidities and dietary compliance.

Recommendation: We recommend that the actual transfer from paediatric to adult care should be structured and include as the minimum written information on the base of diagnosis, follow-up, anthropometric data, comorbidities and dietary compliance.

\section{Communicating with the adolescent/young adult}

Adolescents and young adults may have difficulty communicating with health providers for many reasons. Consequently, providers should be flexible in their communication styles when working with young adult patients. At a face-to-face encounter, it is unclear whether the presence of a parent at the medical visit may be detrimental or supportive to adolescent/young adult communication with the provider. ${ }^{31}$ The presence of a parent can be helpful if the adolescent has not been prepared for independent visits.

Traditional medical care for coeliac patients consists of regular physician visits to evaluate their health, including weight and height measurements (in children), dietary adherence and CD-specific serum antibodies. ${ }^{17}$ Although important, these measures can be time-consuming. In addition, many patients do not visit their physician for regular CD follow-up. ${ }^{35} 43$

Young patients may also have difficulty expressing sensitive concerns in person to a provider, but may do so more readily by email. ${ }^{44}$ Other types of electronic communication, including videoconferencing, SMS messaging, and online consultations, have also been tested in paediatric groups with some success. ${ }^{45}$ Another option can be a self-management e-health coeliac follow-up independent from time and place limitations. Research in other disease areas shows that e-health selfmanagement encourages patients to manage their disease and improve their physical and psychosocial well-being. ${ }^{46}$

\section{Issues that need to be discussed during transition/transfer}

Several issues may be discussed during the transition period ${ }^{47}$ (box 2). Some adolescents/young adults may question their diagnosis and feel the transition period is a natural point for discussing how the diagnosis was made and whether re-evaluation is appropriate. During transition, patients may also realise that they have a long-term condition that requires monitoring throughout adult life. They may also become aware that $\mathrm{CD}$ is linked to increased mortality and comorbidity though the excess risks are generally seen in the first 1-2 years after diagnosis. ${ }^{48-50}$

Of special importance to the adolescent and young adult with CD is adherence to a GFD. In Europe, adherence to a GFD by children and adolescents varies from $44 \%$ to $97 \%,{ }^{51-55}$ and accidental transgressions are common. ${ }^{55}$ At an early age, a GFD may have been prescriptively provided by carers at home, with some involvement of the school. In adolescence, the responsibility of keeping a GFD must be shared by the child and his or her parents. Adherence to a GFD can be very difficult, ${ }^{56} 57$ particularly as the children face new challenges: peer pressure and the stigma of 'being different', school trips and increasing independence from their parents. Adolescence is recognised to be a period when adherence is poor and thus potential risk factors for poor adherence should be recognised. ${ }^{54}$ The little (and historic) data that are available reveal that increasing adherence can be maintained by regular follow-up. ${ }^{58}$ 
Box 2 Topics that may be discussed during transition in coeliac disease (CD)

- Education on the risk of developing complications despite being asymptomatic (there can be a long interval between gluten exposure and the return of symptomatic disease).

- A preventive care plan to increase adolescent/young adult health, even for factors not directly related to $C D,{ }^{122}$ such as education about smoking, ${ }^{123}$ alcohol and drug abuse, ${ }^{124}$ and the importance of physical exercise. ${ }^{125}$ Dietary education that is aimed to avoid deficiencies and to control weight. $^{126}$

- Medical monitoring with laboratory tests and healthcare visits according to the management of all chronic conditions. $^{11}$

- Allocating time and space to discuss with experts about psychological aspects as CD may influence self-image and self-esteem ${ }^{12}$ and interfere with school, education and work. $^{127} 128$

- Sexuality and fertility. Dietary adherence is especially important before conception and during pregnancy as women with untreated $C D$ are more likely to suffer an adverse pregnancy outcome. ${ }^{67} 68$ Several large studies have, however, shown that lifetime fertility is similar in individuals with and without CD. ${ }^{129-131}$

- The gluten-free diet (see text).

Adolescents report lower adherence than younger children, particularly at social events. ${ }^{59}$ Dietary non-adherence in adolescents is associated with increased disease burden, poorer QoL and increased physical symptoms. ${ }^{60}$ Most young people with $\mathrm{CD}$ think that avoiding cancer is the most important reason to adhere to a GFD. ${ }^{61}{ }^{62}$ However, the risk for cancer in CD is much lower than previously presumed, ${ }^{63-65}$ and instead, the risk of osteoporosis ${ }^{66}$ and adverse pregnancy outcome ${ }^{67} 68$ may be bigger issues in individuals with poor adherence. Refractory $\mathrm{CD}$ is very rare in children. ${ }^{69} 70$

Undiagnosed patients with CD may adopt a high-energy diet because of malabsorption. If they continue their eating behaviour after diagnosis, they risk obesity and metabolic syndrome, especially the first year after diagnosis. ${ }^{71}$ Mariani et al ${ }^{61}$ reported that $72 \%$ of Italian adolescents with CD who strictly adhered to the diet were overweight and consumed an unbalanced diet rich in fat and protein, poor in carbohydrate and deficient in calcium, iron and fibre.

After moving away from home, adolescents/young adults with $\mathrm{CD}$ are responsible for purchasing food and cooking, activities previously provided by their parents. Financial issues for the more expensive gluten-free products become more relevant for adolescents/young adults who now live on a limited budget. Adolescents attending college or university face both the difficulty of an abrupt transition from home to a dining room situation with variable provisions for a GFD by their respective institutions and social pressures in adhering to the diet. ${ }^{72}$

Statement: Dietary adherence and consequences of nonadherence are key components for discussion in a transition setting. (C)

Recommendation: We recommend that dietary adherence and consequences of non-adherence are key components for discussion in a transition setting.

\section{Current guidelines for coeliac diagnosis}

Recently, several guidelines have appeared for CD diagnosis reflecting the development in diagnosis of CD (eg, better quality of serological tests and the increased awareness of CD). The NASPGHAN guidelines (USA) from $2005^{73}$ clearly address the questions who to test and how to test using transglutaminase 2 IgA antibody (TG2-IgA) combined with total IgA as a screening tool, followed by referral to a paediatric gastroenterologist and biopsy, with the diagnosis based on a histological analysis. More recently, the ESPGHAN guidelines, ${ }^{15}$ as well as the British Society for Paediatric Gastroenterology guidelines for the diagnosis of $\mathrm{CD},{ }^{74}$ advocate TG2-IgA with total IgA (and IgG-based tests in case of IgA deficiency) as a screening tool. Furthermore, based on an evidence report, ${ }^{75}$ in cases with symptoms and very high TG2-IgA levels $(>10 \times$ the upper limit of normal (ULN)), which gives a high likelihood for concurrent enteropathy, ${ }^{76}$ current ESPGHAN guidelines suggest that in carefully selected cases a biopsy avoidance strategy may be employed by undertaking further supportive tests (HLA-DQ2 and DQ8 determination may rule out $\mathrm{CD}$, and the endomysial antibodies (EMAs) test has a high specificity). If these investigations are consistent with the suspicion of $\mathrm{CD}$, the diagnosis may be established without a biopsy after careful discussion with a paediatric gastroenterologist. Conversely, the adult guidelines from Europe ${ }^{16}$ and the USA $^{17}$ recommend a diagnosis of CD based on TG2-IgA and with biopsy. The US guidelines ${ }^{17}$ consider the pre-test probability and recommend in populations with high pre-test probability to use biopsy in conjunction with TG2-IgA. In populations with a lower pre-test probability, the guidelines suggest waiting for the TG2-IgA results before performing a biopsy. The British guidelines in addition use the EMA test for strengthening the suspicion of CD.

There are good reasons to perform an upper endoscopy with biopsies in adults with suspected CD (box 3). However, some of these issues may not apply in children/adolescence. A further complexity of the CD diagnosis is that the histological analysis may show variability between histopathologists, ${ }^{77}$ and use as the reference standard for the diagnosis of $\mathrm{CD}$ has been challenged. $^{78} 79$ Therefore, it is important, as recommended by all guidelines, to take serology, histology and HLA status into account when there are uncertainties in diagnosis. ${ }^{16}$

\section{Use of biopsy, CD serology and genetic testing in transition to adulthood}

While duodenal biopsies have been the reference standard for diagnosis of $\mathrm{CD}$, recently, a selective no biopsy policy has been

Box 3 Reasons for performing a biopsy in the young adult with a new (suspected) diagnosis of coeliac disease

- Antibodies do not have a $100 \%$ positive predictive value. ${ }^{132-134}$

- Patients with either irritable bowel syndrome or Crohn's disease of the small bowel can be pseudo-improved by adhering to a gluten-free diet. ${ }^{135}$

- Baseline histology can allow assessment of severity (degree of villous atrophy). ${ }^{62} 6687$

- Many patients need an upper endoscopy anyway because they have anaemia or other significant symptoms. ${ }^{136}$

- An upper endoscopy is more easily tolerated by adults and does not typically require general anaesthesia. ${ }^{137}$ 
proposed for some children. ${ }^{15}$ 80-82 In comparison, the policy adopted by gastroenterologists who care for adult patients uniformly requires a biopsy for diagnosis and frequently a follow-up biopsy to document healing for management and prognostic information. The no biopsy policy was adopted by ESPGHAN, but it is not widely accepted in the USA or Australia. This difference between paediatric and adult gastroenterologists may present a topic for discussion in the transition from paediatric to adult care. Both parties will be interested in the quality of the diagnosis of $\mathrm{CD}$ to attain the best quality of care. All diagnostic test results must be available to the accepting physician. Of importance to recognise is that the respective guidelines may not have been followed by the physician who made the initial CD diagnosis. The main themes are as follows:

1. Patient diagnosed according to the 'old' 1990 ESPGHAN criteria. Review of the results of serology testing and the biopsy result will lead to an acceptable diagnosis, allowing the managing physician to continue the care of the patient.

2. Patient diagnosed according to the 'new' 2012 ESPGHAN criteria. ${ }^{15}$ Review of the symptoms, results of serology, HLA status and response to GFD. For levels of TG2-IgA $<10 \times$ ULN, biopsy data must be available.

Different scenarios may be envisaged:

1. The child was symptomatic at diagnosis with malabsorption and the diagnosis based on a TG2-IgA $>10 \times$ ULN, appropriate HLA, positive EMA on a second blood draw and a good response to a GFD. This diagnosis appears to be of high quality that should prompt continuing management with a strict GFD.

2. The child was asymptomatic with, for example, type 1 diabetes mellitus (T1DM) and TG2-IgA $>10 \times$ ULN, appropriate HLA and no biopsy. A single positive tTG IgA test may have been obtained without a second blood draw, confirming a positive tTG or EMA. In this setting, it is necessary to consider whether there may be a temporary coeliac autoimmunity as has been seen in children and adults. ${ }^{83} 84$ The 2012 ESPGHAN criteria are not met in that these criteria do not accept a definitive diagnosis of CD without a biopsy in asymptomatic at-risk groups (a biopsy may be suggested after a gluten load). We urge caution in accepting a diagnosis where diagnostic criteria, as outlined by paediatric guidelines in Europe or North America, have not been fulfilled.
The serological diagnosis of CD is dependent on the quality of the assay employed. For TG2-IgA, the majority of the tests are based on ELISA and eminently suited for assay quality control measures. EMA testing is based on immune fluorescence and with an operator-dependent read-out with possibilities for variability. Yet, EMA testing is the assay with the highest specificity. ${ }^{75}$ As stated in the ESPGHAN diagnostic guideline, to rely on serology, the tests have to be subject to continuous participation in control measures (such as the National External Quality Assurance Scheme (NEQUAS) initiative in Europe). In nonEuropean countries, significant laboratory variability may occur and whether these cut-offs are valid in countries such as the USA are yet to be confirmed. A diagnosis made according to the ESPGHAN guidelines outside of Europe should be considered in the context of this potential uncertainty. ${ }^{85}$

The histological evaluation may also be indeterminate ${ }^{78} 86$ and transition into adult care could be a convenient time for re-evaluation, even when the initial diagnosis is definitive. Table 1 is an overview of differences in the use of histology for diagnostic purposes in children and adults.

Persistent mucosal lesions are common in adults with CD, despite normalisation of serologies. ${ }^{87}$ Concomitant with these lesions are augmented risks of morbidity such as lymphoma ${ }^{62}$ and certain fractures. ${ }^{66}$ Whereas these risks may be lower in children, ${ }^{69}$ and refractory CD and consequently enteropathy associated t-cell lymphoma (EATL) is extremely rare in subjects with CD diagnosed in and treated since childhood, adolescents and young adults with CD may have greater difficulty with dietary adherence, whether accidental or intentional. ${ }^{59}{ }^{88}$ Early identification of such risks may thwart future adverse outcomes and identify those in need of greater surveillance.

Also important is the procedure adopted for transitional follow-up. If the existing diagnostic guidelines have not been met and the diagnosis needs re-evaluation, a new diagnostic approach should be instituted. Serology and histology may be part of this approach. ${ }^{16}$ However, undertaking duodenal biopsies while on a GFD may be uninformative, except for ruling out differential diagnosis and to confirm mucosal healing. After transition, care will be determined dependent upon the results of nutritional, serological, genetic and dietary assessment. ${ }^{16}$ There are four indications for performing a biopsy before or after transition to adult care in some settings with a gluten challenge:

Table 1 Histology in children and adults with suspected coeliac disease (CD)

\begin{tabular}{|c|c|c|}
\hline & Children & Adults \\
\hline $\begin{array}{l}\text { Is a biopsy necessary for } \\
\text { diagnosis? }\end{array}$ & $\begin{array}{l}\text { Dependent on TG2 level, HLA status-if anti-TG2 titres are high } \\
\text { (>10 times the upper limit of normal), the ESPGHAN guidelines } \\
\text { have an option to diagnose CD without duodenal biopsies by } \\
\text { applying a strict protocol with further laboratory tests. }{ }^{15}\end{array}$ & $\begin{array}{l}\text { Recommendation for biopsy-all guidelines emphasise the combined } \\
\text { use of biopsy and serological analyses for diagnosis. }{ }^{16} 17138139 \\
\text { However, in low-resource countries, a positive TG2 with symptom } \\
\text { improvement on a GFD may be considered sufficient for } \\
\text { diagnosis. }^{138139}\end{array}$ \\
\hline $\begin{array}{l}\text { How many biopsies? And } \\
\text { where from? }\end{array}$ & $\begin{array}{l}4-6 \text { including } 2 \text { from bulb, as focality was present in } 18 \% \text {, } \\
\text { patchiness in } 53 \% \text { and at least } 1 \text { normal biopsy fragment was } \\
\text { present in } 36 \% \text { of the cases. Sometimes, changes compatible } \\
\text { with CD are only seen in the bulb, }{ }^{140} 11 \% \text { of patients show only } \\
\text { duodenal bulb involvement, and also bulb sparing, so both } \\
\text { should be taken. }\end{array}$ & At least four, including bulb biopsy. ${ }^{16} 141$ \\
\hline $\begin{array}{l}\text { Adherence to guidelines for } \\
\text { biopsy? }\end{array}$ & $\begin{array}{l}\text { In those without histological evidence of } C D \text {, fewer biopsies are } \\
\text { obtained with none documented from the bulb. Failure to take } \\
\text { the recommended number of biopsies could result in some missed } \\
\text { cases of } C D .^{142}\end{array}$ & $\begin{array}{l}\text { Adherence to submitting } \geq 4 \text { specimens is low in the USA. } \\
\text { Adherence yields a doubling of the diagnostic rate of CD. }{ }^{143}\end{array}$ \\
\hline $\begin{array}{l}\text { Intraepithelial lymphocytes/100 } \\
\text { enterocytes. What is the cut-off } \\
\text { count? }\end{array}$ & $\begin{array}{l}\text { Normal architecture with increased IELs is considered non-specific } \\
\text { in paediatric guidelines. }{ }^{15}\end{array}$ & $\begin{array}{l}\text { Normal architecture with } \geq 25 \text { IELs/100 enterocytes has been } \\
\text { validated as a cut-off point in adults. }{ }^{16} 144\end{array}$ \\
\hline
\end{tabular}


1. if the existing guidelines have not been met;

2. the adolescent has ceased a GFD because he or she doubts the diagnosis;

3. the patient or the physician requires documentation of healing;

4. the presence of symptoms suggests active CD or another diagnosis.

The potential contribution of genetics in ruling out CD in suspect or insufficiently diagnosed cases is important. CD is strongly associated with the HLA-DQ2 and HLA-DQ8 genotypes. $^{89}$ While HLA-DQ2 or DQ8 occurs in $>99 \%$ of people with $\mathrm{CD}$, it is found in $\sim 30 \%$ of the general population, and therefore, a positive genetic test does not confirm a CD diagnosis. $^{90}$

Statement: In adolescents and young adults, biopsy to reconfirm a childhood diagnosis of CD may be considered when the 10 -fold positive tissue transglutaminase antibody result has not been confirmed by positive EMA in a second serology at the time of diagnosis or when the ESPGHAN diagnostic criteria have not been met in a child without duodenal biopsies. Biopsies may also be relevant when the adolescent has ceased a GFD because he or she doubts the diagnosis; the patient or the physician requires documentation of healing; and the presence of symptoms suggests active CD. (C)

Recommendation: We recommend that in adolescents and young adults, routine small intestinal biopsy is not required to reconfirm a childhood diagnosis of CD when the diagnosis has been made according to ESPGHAN or NASPGHAN criteria.

Statement: HLA testing can be used to rule out CD in unclear cases. (B)

Recommendation: We recommend testing for HLA-DQ2 and HLA-DQ8 genotypes in unclear cases.

\section{The gluten challenge}

A gluten challenge after transfer to adult care is normally not needed if diagnostic criteria have been followed, including children diagnosed younger than 2 years of age. ${ }^{91}$ A gluten challenge is indicated when the primary diagnosis of CD was not performed according to standards and guidelines. ${ }^{15} \mathrm{~A}$ second circumstance when a gluten challenge is applicable is when the patient requests proof of the diagnosis, even though the initial diagnosis was performed according to the current standards.

There are no well-established rules in a gluten challenge. The clinical tolerability and the time to relapse vary between patients, but traditionally a 3 months' challenge with moderate to high amounts of gluten has been advocated, ${ }^{92}$ keeping in mind that an enteropathy may occur after an extended period of time. ${ }^{93}$ Before gluten challenge, serology for CD-specific autoantibodies should be performed (duodenal biopsies should preferentially be obtained as well). An increase in CD-specific serum autoantibodies follows histological change. Therefore, if the patient remains asymptomatic, the biopsies should be performed when serology is positive.

\section{Non-coeliac gluten sensitivity in children}

Non-coeliac gluten sensitivity (NCGS) is a differential diagnosis to consider in patients with symptoms of CD, but TG2-IgA and EMA are negative and the histology is normal or near normal (only lymphocytic duodenosis is accepted ${ }^{16}$ ). The genotypes HLA-DQ2/DQ8 may or may not be present. The distinction between wheat allergies with negative IgE antibodies may be difficult. In children, circumstantial evidence suggests that a proportion of children suspected of $\mathrm{CD}$, but with the characteristics mentioned above, may have NCGS. ${ }^{94}$
However, to our knowledge, no study of blinded, placebocontrolled food challenges has been performed in children with gastroenterological symptoms of NCGS. The prevalence of NCGS in children is still unclear, and further studies are needed. ${ }^{95} 96$

Statement: There is as yet no reliable prevalence data on NCGS in children. (C)

Recommendation: We recommend that the diagnosis of NCGS in children/adolescents is not made on a regular basis, but awaits further documentation.

\section{Follow-up}

Follow-up of patients with CD is advocated to ensure dietary adherence, prevent or detect complications or associated conditions including autoimmune thyroid disease, and promote optimal health. ${ }^{169798}$ Data, though limited, suggest continued follow-up improves dietary adherence, whereas lack of regular follow-up seems to be a particular problem for the phase of transition between paediatric and adult care. ${ }^{35} 545899100$ Based on expert opinion, all paediatric patients should be seen at 3-6-month intervals for the first year after diagnosis. Once symptoms have resolved and serological tests for CD have normalised, an annual follow-up visit is recommended. This recommendation is in line with that for adult patients with CD. ${ }^{16}$

CD is associated with fracture risk, ${ }^{101} 102$ predominantly before treatment or in the setting of non-adherence to GFD. ${ }^{103}$ Bone mineral density is frequently depressed in both children ${ }^{104}$ and adults ${ }^{105}$ with CD at the time of diagnosis, and deficits have been shown to correlate with degree of histological severity. ${ }^{106}$ The vast majority of children recover from bone mineral density abnormalities following appropriate therapy. ${ }^{107}$ Thus, dual-energy X-ray absorptiometry should only be considered for young adults at high risk (eg, known history of low-energy bone fractures, dietary non-adherence, established persistent villous atrophy or low body mass index $\left.\left(<20 \mathrm{~kg} / \mathrm{m}^{2}\right)\right)$.

A subset of patients with CD suffer from other diseases of autoimmune pathogenesis such as $\mathrm{T}_{1} \mathrm{DM}^{108}$ and thyroid disease. ${ }^{50} \mathrm{CD}$ is more often seen in patients with Down's syndrome. ${ }^{109}$ Some of these patients may present specific problems in the transition phase and guidelines have been published on transition in T1DM and Down's syndrome. ${ }^{13} 110$ As far as CD is concerned, in patients with T1DM, the GFD may represent a special challenge as diet is already an issue in patients with T1DM

Dermatitis herpetiformis ${ }^{111}{ }^{112}$ is a pruritic skin condition strongly linked to CD. Adolescents and young adults with dermatitis herpetiformis should be aware that medical treatment with dapsone will remedy itch but will have no influence on small intestinal inflammation. Hence, a strict GFD is crucial for this group of patients.

\section{Primary care involvement}

In many countries, adolescents leaving paediatric care are often cared for by a general practitioner rather than by an adult gastroenterologist. Primary care physicians (PCPs) are then also responsible for the healthcare during and after transition. In adults, PCPs may take a major role in care, dependent upon management care programmes and the availability of skilled personnel and local practice.

Some adolescent/young adult patients are also referred to primary care when they are considered healthy after diagnostic work-up information and initial follow-up in secondary care (either with a paediatrician or an adult gastroenterologist). Primary care may also be a suitable care provider if adequate 
resources in terms of personnel skills and laboratory facilities are sufficient for long-term follow-up. In settings where the PCP has access to upper endoscopies with biopsies, the adolescent/young adult be solely cared for by the PCP, provided that relevant skills, a dietician with expertise is available, and that the care results in good self-reported health and normalised laboratory data. Whenever the patient's follow-up is in primary care, a management plan should be followed. ${ }^{16}$ When seeing an adolescent/young adult with $\mathrm{CD}$, the PCP also has to consider an increased risk for other autoimmune diseases. ${ }^{50} 108$ 113-115

Statement: The PCP is often the care provider who is closest to the adult patient with $\mathrm{CD}$. (C)

Recommendation: Primary care may be a suitable care provider if adequate personnel skills and laboratory facilities are sufficient for long-term follow-up, and this may depend on local practice.

\section{Economic issues}

The cost of gluten-free products is often substantially higher than that of gluten-containing products. ${ }^{116-118}$ Different economic models are used to compensate patients with $\mathrm{CD}$, with tax deduction used in parts of Europe (eg, Germany) and North America, ${ }^{119}$ and prescriptions for GFD in many European countries. Prescriptions may, however, only apply to children and in, for example, Austria, Estonia, Finland, Hungary, Spain and Ukraine, adults with $\mathrm{CD}$ receive no government support for extra costs (personal communication, T Koltai, 17 February 2016). While in Italy there are no requirements for the quality of food prescribed, the coeliac society in the UK restricts the prescribed list to essential products, excluding gluten-free foods considered 'unhealthy' such as gluten-free snacks and desserts. In those countries where prescription and rebates on GFD are restricted to children, becoming an adult will incur extra costs of GFD, potentially having a negative impact on dietary adherence.

The cost of healthcare in the transitional period between adolescence and adulthood will vary according to the country of residence. Indeed, in some countries one in three young adults has unmet health needs because of cost. ${ }^{120}$ Special issues arise in the USA with its hybrid healthcare system. Poor children may be covered by Medicaid or Children's Health Insurance Program. In the USA, the Patient Protection and Affordable Care Act (2010) included a provision for a child to remain under his or her parents' insurance plan until age 26 . This act also prevented denial of coverage based on the presence of a chronic condition. However, the parents' insurance may be inadequate to make the needed care affordable.

\section{DISCUSSION}

Seventeen physicians and two representatives from CD patient organisations wrote this consensus report after reviewing the literature on the transition of $\mathrm{CD}$ care from childhood to adulthood.

The strengths of our paper lie in the systematic literature search and the involvement of patient organisation representatives. However, we acknowledge several weaknesses, including a low level of evidence, and we are not aware of any randomised trials on transition in CD. Despite the lack of CD-specific evidence, we have tried to make statements and recommendations, sometimes based on inference from data in other chronic diseases and sometimes on our own pooled clinical experience. We have listed several recommendations of care adding to more general recommendations of diagnostics and management in CD. ${ }^{15-17}$ Still, we understand that countries, and thereby the conditions for care of delivery, differ. We also recognise that resource limitations will hinder some providers from offering joint clinics and follow-up as suggested.

We believe that we offer a working approach to adolescents and young adults who were once diagnosed without a small intestinal biopsy ${ }^{15}$ and now enter adult healthcare where biopsy is still generally recommended to diagnose the condition. ${ }^{16} 17$ That said, we recognise that there is international variation of practice based on social practice and that individual patient preferences may also influence the transition process.

We recommend that the diagnosis be re-evaluated only when made outside current ESPGHAN or NASPGHAN recommendations or when the patient questions his/her diagnosis. That does not mean that a paediatric $\mathrm{CD}$ diagnosis is more erroneous than a diagnosis made by an adult gastroenterologist.

The implementation of a systematic transition policy in CD has been limited by a lack of clinical guidelines based on outcome-related research and clear and consistent definitions. ${ }^{4}$ In the absence of solid evidence, different models of transition will be likely developed locally. We still do not know if a standardised protocol-driven transition process is superior to a process that varies both nationally and internally. These differences will contribute to the differences that exist between the different healthcare systems. Models of transition ${ }^{42}$ will eventually need to be evaluated in randomised controlled trials with clear patient outcome measures. It is crucial to know to what extent a wellstructured and planned transition will influence adherence to a GFD, which in CD is imperative for restoration of health and well-being. This aspect will depend on the prevalence and quality of complications, as well as on health-related QoL. ${ }^{57} 121$ Socio-economic effectiveness and outcomes of care of the different models should also be carefully evaluated. Further studies are needed to identify and remove barriers ${ }^{20}$ to transition.

\section{Author affiliations}

'Department of Medical Epidemiology and Biostatistics, Karolinska Institutet, Stockholm, Sweden

${ }^{2}$ Department of Paediatrics, Örebro University Hospital, Örebro, Sweden

${ }^{3}$ Division of Epidemiology and Public Health, School of Medicine, University of Nottingham, Nottingham, UK

${ }^{4}$ Division of Family Medicine, Karolinska Institutet, Sweden

${ }^{5}$ Department of Medicine and Surgery, University of Salerno, Salerno, Italy

${ }^{6}$ University of California, San Diego (UCSD), San Diego, California, USA

${ }^{7}$ Celiac Disease Foundation, Los Angeles, California, USA

${ }^{8}$ Celiac Disease Center at Columbia University, New York, New York, USA

${ }^{9}$ Division of Gastroenterology, Nationwide Children's Hospital, Columbus, Ohio, USA

${ }^{10}$ Primary Care and General Practice, School of Medicine, Pharmacy and Health,

Durham University, Stockton on Tees, UK

${ }^{11}$ Ludwig-Maximilians-University of Munich, Dr. von Hauner Children's Hospital, Munich, Germany

${ }^{12}$ Hungary (for the Association of European Coeliac Societies, AOECS), Budapest,

Hungary

${ }^{13}$ Department of Gastroenterology and Centre for Immune Regulation, Oslo

University Hospital Rikshospitalet, Oslo, Norway

${ }^{14}$ Department of Paediatrics, Leiden University Medical Center, Leiden, The

Netherlands

${ }^{15}$ Division of Gastroenterology and Hepatology, Department of Immunology Mayo

Clinic, Rochester, Minnesota, USA

${ }^{16}$ Columbia University Medical Center-Division of Paediatric Gastroenterology, New York, New York, USA

${ }^{17}$ Anatomical Pathology, Faculty of Health and Medicine, University of Newcastle, School of Medicine \& Public Health, Newcastle, Australia

${ }^{18}$ Academic Unit of Gastroenterology, Royal Hallamshire Hospital \& University of Sheffield, Sheffield, UK

${ }^{19}$ Institute of Gastroenterology, Nutrition and Liver Diseases Schneider Children's Medical Center of Israel, Tel-Aviv University, Tel Aviv, Israel

${ }^{20}$ Department of Medical Translational Sciences \& European Laboratory for the Investigation of Food Induced Diseases, University Federico II, Naples, Italy

${ }^{21}$ Hans Christian Andersen Children's Hospital, Odense University Hospital, Odense C, Denmark 
Correction notice This article has been corrected since it published Online First. An Open Access licence has been added.

Twitter Follow Marilyn Geller at @ceoatcdf

Contributors JFL and SH initiated the study on the suggestion of JAM. JFL coordinated the study and wrote the first draft. All authors contributed to the literature searches, contributed to the writing of the manuscript and approved the final version of the manuscript.

Funding JFL was supported by the Swedish Research Council (522-2A09-195) and the Swedish Society of Medicine while writing the draft of this paper. DSS received an educational grant from Biocard and Simtomax to undertake an investigator-led research study on point of care tests, an educational grant from Dr Schär (a gluten-free food manufacturer) to undertake an investigator-led research study on gluten sensitivity. SH received unconditional grants from the NovoNordiskFonden, the Health Research Funds of the Region of Southern Denmark, the Odense University Hospital.

Competing interests PHRG: scientific advisory board of Alvine Pharmaceuticals and ImmusanT. JAM: consultant for Alba Pharmaceuticals, Alvine Therapeutics, Flamentera, 2GPharma Boeringer-Ingelheim and ImmusanT. KEAL: ImmusanT, Regeneron and Alvine Pharmaceuticals. DSS: has received an educational grant from Coeliac UK, Biocard, Simtomax and Dr Schär (a gluten-free food manufacturer) to undertake an investigator-led research study on CD and/or gluten sensitivity. IH: Abbvie Scientific Advisory Group Member. RS: consultant to Bioline. SK: Received funding for a CD-related research projects from Nestle, R-Biopharm, Schär, Phadia-ThermoFisher, Eurospital, Euroimmun, Inova. NR: clinical advisory board for ImmusanT. SH: educational grant from Thermo-Fisher, advisory board for Simtomax.

Provenance and peer review Not commissioned; externally peer reviewed.

Open Access This is an Open Access article distributed in accordance with the Creative Commons Attribution Non Commercial (CC BY-NC 4.0) license, which permits others to distribute, remix, adapt, build upon this work non-commercially, and license their derivative works on different terms, provided the original work is properly cited and the use is non-commercial. See: http://creativecommons.org/ licenses/by-nc/4.0/

\section{REFERENCES}

1 Child and Adolescent Health Measurement Initiative. 2011/12 National Survey of Children's Health, 2012. http://www.childhealthdata.org/browse/survey/results? $q=2625 \& r=1$ Access date: Dec 2, 2015

2 McManus MA, Pollack LR, Cooley WC, et al. Current status of transition preparation among youth with special needs in the United States. Pediatrics 2013;131:1090-7.

3 Sebastian S, Jenkins H, McCartney S, et al. The requirements and barriers to successful transition of adolescents with inflammatory bowel disease: differing perceptions from a survey of adult and paediatric gastroenterologists. J Crohns Colitis 2012;6:830-44.

4 Ludvigsson JF, Leffler DA, Bai JC, et al. The Oslo definitions for coeliac disease and related terms. Gut 2013;62:43-52.

5 Rubio-Tapia A, Ludvigsson JF, Brantner TL, et al. The prevalence of celiac disease in the United States. Am J Gastroenterol 2012;107:1538-44; quiz 1537, 1545.

6 Myléus A, Ivarsson A, Webb C, et al. Celiac disease revealed in $3 \%$ of Swedish 12-year-olds born during an epidemic. J Pediatr Gastroenterol Nutr 2009;49:170-6.

7 Ludvigsson JF, Rubio-Tapia A, van Dyke CT, et al. Increasing incidence of celiac disease in a North American population. Am J Gastroenterol 2013;108:818-24.

8 Zingone F, West J, Crooks CJ, et al. Socioeconomic variation in the incidence of childhood coeliac disease in the UK. Arch Dis Child 2015;100:466-73.

9 Rubio-Tapia A, Kyle RA, Kaplan EL, et al. Increased prevalence and mortality in undiagnosed celiac disease. Gastroenterology 2009;137:88-93.

10 Catassi C, Kryszak D, Bhatti B, et al. Natural history of celiac disease autoimmunity in a USA cohort followed since 1974. Ann Med 2010;42:530-8.

11 Cooley WC, Sagerman PJ, American Academy of Pediatrics; American Academy of Family Physicians; American College of Physicians; Transitions Clinical Report Authoring Group. Supporting the health care transition from adolescence to adulthood in the medical home. Pediatrics 2011;128:182-200.

12 Sable C, Foster E, Uzark K, et al. Best practices in managing transition to adulthood for adolescents with congenital heart disease: the transition process and medical and psychosocial issues: a scientific statement from the American Heart Association. Circulation 2011;123:1454-85.

13 Peters A, Laffel L, American Diabetes Association Transitions Working Group. Diabetes care for emerging adults: recommendations for transition from pediatric to adult diabetes care systems: a position statement of the American Diabetes Association, with representation by the American College of Osteopathic Family Physicians, the American Academy of Pediatrics, the American Association of Clinical Endocrinologists, the American Osteopathic Association, the Centers for Disease Control and Prevention, Children with Diabetes, The Endocrine Society, the International Society for Pediatric and Adolescent Diabetes, Juvenile Diabetes
Research Foundation International, The National Diabetes Education Program, and the Pediatric Endocrine Society (formerly Lawson Wilkins Pediatric Endocrine Society). Diabetes Care 2011;34:2477-85.

14 Elli L, Maieron R, Martelossi S, et al., Italian Society of Paediatric Gastroenterology, Hepatology and Nutrition (SIGENP), Italian Association of Hospital Gastroenterologists and Endoscopists (AIGO), Italian Society of Endoscopy (SIED), Italian Society of Gastroenterology (SIGE). Transition of gastroenterological patients from paediatric to adult care: A position statement by the Italian Societies of Gastroenterology. Dig Liver Dis 2015;47:734-40.

15 Husby S, Koletzko S, Korponay-Szabó IR, et al. European Society for Pediatric Gastroenterology, Hepatology, and Nutrition guidelines for the diagnosis of coeliac disease. J Pediatr Gastroenterol Nutr 2012;54:136-60.

16 Ludvigsson JF, Bai JC, Biagi F, et al. Diagnosis and management of adult coeliac disease: guidelines from the British Society of Gastroenterology. Gut 2014:63:1210-28.

17 Rubio-Tapia A, Hill ID, Kelly CP, et al. ACG clinical guidelines: diagnosis and management of celiac disease. Am J Gastroenterol 2013;108:656-76; quiz 77.

18 Guyatt GH, Oxman AD, Vist GE, et al. GRADE: an emerging consensus on rating quality of evidence and strength of recommendations. BMJ 2008;336:924-6.

19 Rosen D. Between two worlds: bridging the cultures of child health and adult medicine. J Adolesc Health 1995;17:10-16.

20 Bryon M, Madge S. Transition from paediatric to adult care: psychological principles. J R Soc Med 2001;94 40):5-7.

21 Stam H, Hartman EE, Deurloo JA, et al. Young adult patients with a history of pediatric disease: impact on course of life and transition into adulthood. J Adolesc Health 2006;39:4-13.

22 Ludvigsson JF, Ansved P, Fälth-Magnusson K, et al. Symptoms and Signs Have Changed in Swedish Children With Coeliac Disease. J Pediatr Gastroenterol Nutr 2004;38:181-6.

23 Meazza C, Pagani S, Laarej K, et al. Short stature in children with coeliac disease. Pediatr Endocrinol Rev 2009;6:457-63.

24 Troncone R, Kosova R. Short stature and catch-up growth in celiac disease. J Pediatr Gastroenterol Nutr 2010;51(Suppl 3):S137-8.

25 Salardi S, Cacciari E, Volta U, et al. Growth and adult height in atypical coeliac patients, with or without growth hormone deficiency. J Pediatr Endocrinol Metab 2005;18:769-75.

26 Sonti R, Lebwohl B, Lewis SK, et al. Men with celiac disease are shorter than their peers in the general population. Eur I Gastroenterol Hepatol 2013;25: 1033-7.

27 Weiss B, Skourikhin Y, Modan-Moses D, et al. Is adult height of patients with celiac disease influenced by delayed diagnosis? Am I Gastroenterol 2008:103:1770-4.

28 Abaci A, Esen I, Unuvar T, et al. Two cases presenting with pubertal delay and diagnosed as Celiac disease. Clin Pediatr (Phila) 2008;47:607-9.

29 Kumar PJ, Walker-Smith J, Milla P, et al. The teenage coeliac: follow up study of 102 patients. Arch Dis Child 1988:63:916-20.

30 Reiss JG, Gibson RW, Walker LR. Health care transition: youth, family, and provider perspectives. Pediatrics 2005;115:112-20.

31 Beresford BA, Sloper P. Chronically ill adolescents' experiences of communicating with doctors: a qualitative study. J Adolesc Health 2003;33:172-9.

32 Kyngas H, Barlow J. Diabetes: an adolescent's perspective. J Adv Nurs 1995:22:941-7.

33 Kyngas $\mathrm{H}$, Hentinen $\mathrm{M}$, Barlow JH. Adolescents' perceptions of physicians, nurses, parents and friends: help or hindrance in compliance with diabetes self-care? J Adv Nurs 1998:27:760-9.

34 O'Leary C, Wieneke $\mathrm{P}$, Healy M, et al. Celiac disease and the transition from childhood to adulthood: a 28-year follow-up. Am I Gastroenterol 2004;99:2437-41.

35 Mozer-Glassberg Y, Zevit N, Rosenbach Y, et al. Follow-up of children with celiac disease-lost in translation? Digestion 2011;83:283-7.

36 Viner R. Transition from paediatric to adult care. Bridging the gaps or passing the buck? Arch Dis Child 1999;81:271-5.

37 Dabadie A, Troadec F, Heresbach D, et al. Transition of patients with inflammatory bowel disease from pediatric to adult care. Gastroenterol Clin Biol 2008:32:451-9.

38 Zeisler B, Hyams JS. Transition of management in adolescents with IBD. Nat Rev Gastroenterol Hepatol 2014;11:109-15.

39 Annunziato RA, Emre S, Shneider BL, et al. Transitioning health care responsibility from caregivers to patient: a pilot study aiming to facilitate medication adherence during this process. Pediatr Transplant 2008;12:309-15.

40 Nakhla M, Daneman D, To T, et al. Transition to adult care for youths with diabetes mellitus: findings from a Universal Health Care System. Pediatrics 2009;124:e1134-41.

41 McDonagh JE, Southwood TR, Shaw KL, et al. The impact of a coordinated transitional care programme on adolescents with juvenile idiopathic arthritis Rheumatology (Oxford) 2007;46:161-8.

42 Crowley R, Wolfe I, Lock K, et al. Improving the transition between paediatric and adult healthcare: a systematic review. Arch Dis Child 2011;96:548-53. 
43 Bebb JR, Lawson A, Knight T, et al. Long-term follow-up of coeliac disease-what do coeliac patients want? Aliment Pharmacol Ther 2006;23:827-31.

44 Harvey K, Churchill D, Crawford P, et al. Health communication and adolescents: what do their emails tell us? Fam Pract 2008:25:304-11.

45 Gentles SJ, Lokker C, McKibbon KA. Health information technology to facilitate communication involving health care providers, caregivers, and pediatric patients: a scoping review. J Med Internet Res 2010;12:e22.

46 Wildevuur SE, Simonse LW. Information and communication technology-enabled person-centered care for the "big five" chronic conditions: scoping review. J Med Internet Res 2015;17:e77.

47 Nagra A, McGinnity PM, Davis N, et al. Implementing transition: Ready Steady Go. Arch Dis Child Educ Pract Ed 2015;100:313-20.

48 Ludvigsson JF, Montgomery SM, Ekbom A, et al. Small-intestinal histopathology and mortality risk in celiac disease. JAMA 2009;302:1171-8.

49 Ludvigsson JF, James S, Askling J, et al. Nationwide cohort study of risk of ischemic heart disease in patients with celiac disease. Circulation 2011;123:483-90.

50 Elfström P, Montgomery SM, Kämpe 0, et al. Risk of thyroid disease in individuals with celiac disease. J Clin Endocrinol Metab 2008;93:3915-21.

51 Charalampopoulos D, Panayiotou J, Chouliaras G, et al. Determinants of adherence to gluten-free diet in Greek children with coeliac disease: a cross-sectional study. Eur J Clin Nutr 2013;67:615-19.

52 Hopman EG, Koopman HM, Wit JM, et al. Dietary compliance and health-related quality of life in patients with coeliac disease. Eur J Gastroenterol Hepatol 2009;21:1056-61

53 Roma E, Roubani A, Kolia E, et al. Dietary compliance and life style of children with coeliac disease. J Hum Nutr Diet 2010;23:176-82.

54 Errichiello S, Esposito O, Di Mase R, et al. Celiac disease: predictors of compliance with a gluten-free diet in adolescents and young adults. J Pediatr Gastroenterol Nutr 2010;50:54-60.

55 Tapsas D, Fälth-Magnusson K, Högberg L, et al. Swedish children with celiac disease comply well with a gluten-free diet, and most include oats without reporting any adverse effects: a long-term follow-up study. Nutr Res 2014;34:436-41.

56 Lamontagne P, West GE, Galibois I. Quebecers with celiac disease: analysis of dietary problems. Can J Diet Pract Res 2001;62:175-81.

57 van Doorn RK, Winkler LM, Zwinderman KH, et al. CDDUX: a disease-specific health-related quality-of-life questionnaire for children with celiac disease. J Pediatr Gastroenterol Nutr 2008;47:147-52.

58 Bardella MT, Molteni N, Prampolini L, et al. Need for follow up in coeliac disease. Arch Dis Child 1994;70:211-13.

59 MacCulloch K, Rashid M. Factors affecting adherence to a gluten-free diet in children with celiac disease. Paediatr Child Health 2014;19:305-9.

60 Wagner G, Berger $G$, Sinnreich $U$, et al. Quality of life in adolescents with treated coeliac disease: influence of compliance and age at diagnosis. J Pediatr Gastroenterol Nutr 2008;47:555-61.

61 Mariani P, Viti MG, Montuori M, et al. The gluten-free diet: a nutritional risk factor for adolescents with celiac disease? J Pediatr Gastroenterol Nutr 1998;27:519-23.

62 Lebwohl B, Granath F, Ekbom A, et al. Mucosal healing and risk for lymphoproliferative malignancy in celiac disease: a population-based cohort study. Ann Intern Med 2013;159:169-75.

63 Mearin ML, Catassi C, Brousse N, et al. European multi-centre study on coeliac disease and non-Hodgkin lymphoma. Eur J Gastroenterol Hepatol 2006;18:187-94.

64 Elfström P, Granath F, Ekström Smedby K, et al. Risk of Lymphoproliferative Malignancy in Relation to Small Intestinal Histopathology Among Patients With Celiac Disease. J Natl Cancer Inst 2011;103:436-44.

65 Elfström P, Granath F, Ye W, et al. Low risk of gastrointestinal cancer among patients with celiac disease, inflammation, or latent celiac disease. Clin Gastroenterol Hepatol 2012;10:30-6.

66 Lebwohl B, Michaëlsson K, Green PH, et al. Persistent mucosal damage and risk of fracture in celiac disease. J Clin Endocrinol Metab 2014;99:609-16.

67 Ludvigsson JF, Montgomery SM, Ekbom A. Celiac disease and risk of adverse fetal outcome: a population-based cohort study. Gastroenterology 2005;129:454-63.

68 Saccone G, Berghella V, Sarno L, et al. Celiac disease and obstetric complications: a systematic review and metaanalysis. Am J Obstet Gynecol 2016;214:225-34.

69 Vécsei $\mathrm{E}$, Steinwendner $\mathrm{S}$, Kogler $\mathrm{H}$, et al. Follow-up of pediatric celiac disease: value of antibodies in predicting mucosal healing, a prospective cohort study. BMC Gastroenterol 2014;14:28.

70 Ghazzawi Y, Rubio-Tapia A, Murray JA, et al. Mucosal healing in children with treated celiac disease. J Pediatr Gastroenterol Nutr 2014;59:229-31.

71 Tortora R, Capone P, De Stefano G, et al. Metabolic syndrome in patients with coeliac disease on a gluten-free diet. Aliment Pharmacol Ther 2015;41:352-9.

72 Panzer RM, Dennis M, Kelly CP, et al. Navigating the gluten-free diet in college. J Pediatr Gastroenterol Nutr 2012;55:740-4.

73 Hill ID, Dirks MH, Liptak GS, et al. Guideline for the diagnosis and treatment of celiac disease in children: recommendations of the North American Society for
Pediatric Gastroenterology, Hepatology and Nutrition. J Pediatr Gastroenterol Nutr 2005:40:1-19.

74 Murch S, Jenkins $H$, Auth $M$, et al. Joint BSPGHAN and Coeliac UK guidelines for the diagnosis and management of coeliac disease in children. Arch Dis Child 2013;98:806-11.

75 Giersiepen K, Lelgemann M, Stuhldreher N, et al. Accuracy of diagnostic antibody tests for coeliac disease in children: summary of an evidence report. J Pediatr Gastroenterol Nutr 2012;54:229-41.

76 Hill PG, Holmes GK. Coeliac disease: a biopsy is not always necessary for diagnosis. Aliment Pharmacol Ther 2008;27:572-7.

77 Arguelles-Grande C, Tennyson CA, Lewis SK, et al. Variability in small bowel histopathology reporting between different pathology practice settings: impact on the diagnosis of coeliac disease. J Clin Pathol 2012;65:242-7.

78 Taavela J, Koskinen $\mathrm{O}$, Huhtala $\mathrm{H}$, et al. Validation of morphometric analyses of small-intestinal biopsy readouts in celiac disease. PLoS ONE 2013;8:e76163.

79 Marsh MN, Johnson MW, Rostami K. Mucosal histopathology in celiac disease: a rebuttal of Oberhuber's sub-division of Marsh III. Gastroenterol Hepatol Bed Bench 2015;8:99-109.

80 McNeish AS, Harms HK, Rey J, et al. The diagnosis of coeliac disease. A commentary on the current practices of members of the European Society for Paediatric Gastroenterology and Nutrition (ESPGAN). Arch Dis Child 1979:54:783-6.

81 Guandalini S, Ventura A, Ansaldi N, et al. Diagnosis of coeliac disease: time for a change? Arch Dis Child 1989;64:1320-4; discussion 24-5.

82 [No authors listed]. Revised criteria for diagnosis of coeliac disease. Report of Working Group of European Society of Paediatric Gastroenterology and Nutrition. Arch Dis Child 1990;65:909-11.

83 Liu E, Bao F, Barriga K, et al. Fluctuating transglutaminase autoantibodies are related to histologic features of celiac disease. Clin Gastroenterol Hepatol 2003;1:356-62.

84 Mahadev S, Bhagat G, Green PH. Transient celiac autoimmunity in an adult. J Clin Gastroenterol 2011;45:912-13.

85 Gidrewicz D, Potter K, Trevenen CL, et al. Evaluation of the ESPGHAN Celiac Guidelines in a North American Pediatric Population. Am J Gastroenterol 2015;110:760-7.

86 Mubarak A, Nikkels $P$, Houwen $R$, et al. Reproducibility of the histological diagnosis of celiac disease. Scand J Gastroenterol 2011;46:1065-73.

87 Lebwohl B, Murray JA, Rubio-Tapia A, et al. Predictors of persistent villous atrophy in coeliac disease: a population-based study. Aliment Pharmacol Ther 2014;39:488-95.

88 Altobelli E, Paduano R, Gentile T, et al. Health-related quality of life in children and adolescents with celiac disease: survey of a population from central Italy. Health Qual Life Outcomes 2013;11:204.

89 Wolters VM, Wijmenga C. Genetic background of celiac disease and its clinical implications. Am J Gastroenterol 2008;103:190-5.

90 Molina-Infante J, Santolaria S, Sanders DS, et al. Systematic review: noncoeliac gluten sensitivity. Aliment Pharmacol Ther 2015;41:807-20.

91 Misak Z, Hojsak I, Jadresin 0, et al. Diagnosis of coeliac disease in children younger than 2 years. J Pediatr Gastroenterol Nutr 2013;56:201-5.

92 Rolles CJ, McNeish AS. Standardised approach to gluten challenge in diagnosing childhood coeliac disease. Br Med J 1976;1:1309-11.

93 Mäki M, Lähdeaho ML, Hällström O, et al. Postpubertal gluten challenge in coeliac disease. Arch Dis Child 1989;64:1604-7.

94 Francavilla R, Cristofori F, Castellaneta S, et al. Clinical, serologic, and histologic features of gluten sensitivity in children. J Pediatr 2014;164:463-7.e1.

95 Tanpowpong P, Ingham TR, Lampshire PK, et al. Coeliac disease and gluten avoidance in New Zealand children. Arch Dis Child 2012:97:12-16.

96 Tanpowpong P, Broder-Fingert S, Katz AJ, et al. Predictors of gluten avoidance and implementation of a gluten-free diet in children and adolescents without confirmed celiac disease. J Pediatr 2012;161:471-5.

97 Hall NJ, Rubin G, Charnock A. Systematic review: adherence to a gluten-free diet in adult patients with coeliac disease. Aliment Pharmacol Ther 2009;30: 315-30.

98 McLarnon A. Thyroid cancer: Pazopanib alone is not effective against anaplastic thyroid cancer. Nat Rev Endocrinol 2012;8:565.

99 Barnea L, Mozer-Glassberg Y, Hojsak I, et al. Pediatric celiac disease patients who are lost to follow-up have a poorly controlled disease. Digestion 2014;90:248-53.

100 Kurppa K, Lauronen O, Collin P, et al. Factors associated with dietary adherence in celiac disease: a nationwide study. Digestion 2012;86:309-14.

101 Ludvigsson JF, Michaelsson K, Ekbom A, et al. Coeliac disease and the risk of fractures - a general population-based cohort study. Aliment Pharmacol Ther 2007:25:273-85.

102 Heikkilä K, Pearce J, Mäki M, et al. Celiac disease and bone fractures: a systematic review and meta-analysis. J Clin Endocrinol Metab 2015;100:25-34.

103 Vasquez H, Mazure R, Gonzalez D, et al. Risk of fractures in celiac disease patients: a cross-sectional, case-control study. Am J Gastroenterol 2000;95:183-9.

104 Kalayci AG, Kansu A, Girgin N, et al. Bone mineral density and importance of a gluten-free diet in patients with celiac disease in childhood. Pediatrics 2001;108:E89. 
105 Kemppainen $T$, Kroger $H$, Janatuinen $\mathrm{E}$, et al. Osteoporosis in adult patients with celiac disease. Bone 1999;24:249-55.

106 Jatla M, Zemel BS, Bierly P, et al. Bone mineral content deficits of the spine and whole body in children at time of diagnosis with celiac disease. J Pediatr Gastroenterol Nutr 2009;48:175-80.

107 Mora S, Barera G, Beccio S, et al. Bone density and bone metabolism are normal after long-term gluten-free diet in young celiac patients. Am J Gastroenterol 1999:94:398-403.

108 Elfström P, Sundström J, Ludvigsson JF. Systematic review with meta-analysis: associations between coeliac disease and type 1 diabetes. Aliment Pharmacol The 2014:40:1123-32.

109 Marild K, Stephansson O, Grahnquist L, et al. Down syndrome is associated with elevated risk of celiac disease: a nationwide case-control study. J Pediatr 2013;163:237-42

110 Schrander-Stumpel CT, Sinnema M, van den et al. Healthcare transition in persons with intellectual disabilities: general issues, the Maastricht model, and Prader-Willi syndrome. Am J Med Genet C Semin Med Genet 2007;145C:241-7.

111 Bolotin D, Petronic-Rosic V. Dermatitis herpetiformis. Part II. Diagnosis, management, and prognosis. J Am Acad Dermatol 2011;64:1027-33; quiz 33-4.

112 Bolotin D, Petronic-Rosic V. Dermatitis herpetiformis. Part I. Epidemiology, pathogenesis, and clinical presentation. J Am Acad Dermatol 2011;64:1017-24; quiz 25-6.

113 Elfström P, Montgomery SM, Kämpe 0 , et al. Risk of primary adrenal insufficiency in patients with celiac disease. J Clin Endocrinol Metab 2007;92:3595-8.

114 Ludvigsson JF, Lindelöf $B$, Zingone $F$, et al. Psoriasis in a nationwide cohort study of patients with celiac disease. J Invest Dermatol 2011:131:2010-16.

115 Zhernakova A, Stahl EA, Trynka G, et al. Meta-analysis of genome-wide association studies in celiac disease and rheumatoid arthritis identifies fourteen non-HLA shared loci. PLoS Genet 2011;7:e1002004.

116 Stevens L, Rashid M. Gluten-free and regular foods: a cost comparison. Can J Diet Pract Res 2008:69:147-50.

117 Long KH, Rubio-Tapia A, Wagie AE, et al. The economics of coeliac disease: a population-based study. Aliment Pharmacol Ther 2010;32:261-9.

118 Singh J, Whelan K. Limited availability and higher cost of gluten-free foods. J Hum Nutr Diet 2011:24:479-86.

119 Pinto-Sanchez MI, Verdu EF, Gordillo MC, et al. Tax-deductible provisions for gluten-free diet in Canada compared with systems for gluten-free diet coverage available in various countries. Can J Gastroenterol Hepatol 2015:29:104-10.

120 Callahan ST, Cooper WO. Access to health care for young adults with disabling chronic conditions. Arch Pediatr Adolesc Med 2006:160:178-82.

121 Skjerning $\mathrm{H}$, Mahony RO, Husby S, et al. Health-related quality of life in children and adolescents with celiac disease: patient-driven data from focus group interviews. Qual Life Res 2014:23:1883-94.

122 Boisen KA, Hertz PG, Blix C, et al. Is HEADS in our heads? Health risk behavior is not routinely discussed with young people with chronic conditions. Int I Adolesc Med Health 2015.

123 Walker JF, Loprinzi PD. Longitudinal examination of predictors of smoking cessation in a national sample of U.S. adolescent and young adult smokers. Nicotine Tob Res 2014;16:820-7.

124 VanKim NA, Laska MN, Ehlinger $E$, et al. Understanding young adult physical activity, alcohol and tobacco use in community colleges and 4-year post-secondary institutions: A cross-sectional analysis of epidemiological surveillance data. BMC Public Health 2010;10:208.

125 Passananti V, Santonicola A, Bucci C, et al. Bone mass in women with celiac disease: role of exercise and gluten-free diet. Dig Liver Dis 2012;44:379-83.

126 Shepherd SJ, Gibson PR. Nutritional inadequacies of the gluten-free diet in both recently-diagnosed and long-term patients with coeliac disease. J Hum Nutr Diet 2013;26:349-58.

127 Calsbeek H, Rijken M, Dekker J, et al. Disease characteristics as determinants of the labour market position of adolescents and young adults with chronic digestive disorders. Eur J Gastroenterol Hepatol 2006;18:203-9.

128 Calsbeek H, Rijken M, Bekkers MJ, et al. School and leisure activities in adolescents and young adults with chronic digestive disorders: impact of burden of disease. Int J Behav Med 2006:13:121-30.

129 Zugna D, Richiardi L, Akre 0, et al. A nationwide population-based study to determine whether coeliac disease is associated with infertility. Gut 2010;59:1471-5.

130 Tata LJ, Card TR, Logan RF, et al. Fertility and pregnancy-related events in women with celiac disease: a population-based cohort study. Gastroenterology 2005; 128:849-55.

131 Zugna D, Richiardi L, Akre 0, et al. Celiac disease is not a risk factor for infertility in men. Fertil Steril 2011;95:1709-13.e3.

132 Hopper AD, Cross SS, Hurlstone DP, et al. Pre-endoscopy serological testing for coeliac disease: evaluation of a clinical decision tool. BMJ 2007:334:729.

133 Hadithi M, von Blomberg BM, Crusius JB, et al. Accuracy of serologic tests and HLA-DQ typing for diagnosing celiac disease. Ann Intern Med 2007;147: 294-302.

134 Mooney PD, Wong SH, Johnston AJ, et al. Increased Detection of Celiac Disease With Measurement of Deamidated Gliadin Peptide Antibody Before Endoscopy. Clin Gastroenterol Hepatol 2015:13:1278-84.e1.

135 Aziz I, Branchi F, Pearson K, et al. A study evaluating the bidirectional relationship between inflammatory bowel disease and self-reported non-celiac gluten sensitivity. Inflamm Bowel Dis 2015;21:847-53.

136 Goddard AF, James MW, McIntyre AS, et al. Guidelines for the management of iron deficiency anaemia. Gut 2011;60:1309-16.

137 Irvine AJ, Sanders DS, Hopper AD, et al. How does tolerability of double balloon enteroscopy compare to other forms of endoscopy? Frontline Gastroenterology 2016;7:41-6.

138 Bai JC, Fried M, Corazza GR, et al. World gastroenterology organisation global guidelines on celiac disease. J Clin Gastroenterol 2013;47:121-6.

139 Kelly CP, Bai JC, Liu E, et al. Advances in diagnosis and management of celiac disease. Gastroenterology 2015;148:1175-86.

140 Weir DC, Glickman JN, Roiff T, et al. Variability of histopathological changes in childhood celiac disease. Am J Gastroenterol 2010;105:207-12.

141 Rashid M, MacDonald A. Importance of duodenal bulb biopsies in children for diagnosis of celiac disease in clinical practice. BMC Gastroenterol 2009; $9: 78$.

142 Ofei S, Boyle B, Ediger T, et al. Adherence to Endoscopy Biopsy Guidelines for Celiac Disease. J Pediatr Gastroenterol Nutr 2015;61:440-4.

143 Lebwohl B, Kapel RC, Neugut Al, et al. Adherence to biopsy guidelines increases celiac disease diagnosis. Gastrointest Endosc 2011;74:103-9.

144 Walker MM, Murray JA, Ronkainen J, et al. Detection of Celiac Disease and Lymphocytic Enteropathy by Parallel Serology and Histopathology in a Population-Based Study. Gastroenterology 2010;139:112-19. 